\section{O Brasil referenciado em skins do jogo SMITE*}

Brazil referenced in skins from
the SMITE game

Bruno BRANDÃO (UESC) bruno.branda05@gmail.com

Elaine Cristina Medeiros FROSSARD (UESC) ecmfrossard@gmail.com

Recebido em: 08 de ago. de 2020. Aceito em: 11 de set. de 2020.

*Um recorte deste trabalho, "O cangaço referenciado no jogo SMITE", foi apresentado na modalidade comunicação oral no X Seminário de Pesquisa e Extensão em Letras, realizado na Universidade Estadual de Santa Cruz (UESC) em 8 dez. 2019.
BRANDÃO, Bruno; FROSSARD,

Elaine Cristina Medeiros. O Brasil referenciado em skins do jogo SMITE. Entrepalavras, Fortaleza, v. 11, n. 2, e1943, p. 1-24, maio-ago./2021. DOI: $10.22168 / 2237-6321-21943$.

Resumo: O presente estudo objetiva identificar as referências culturais e linguísticas (primariamente fonéticofonológicas) em relação ao Brasil em SMITE. Nesse contexto, as skins (modificações estéticas para personagens do jogo) Vamana Cangaceiro e Globeneith, bem como seus respectivos conjuntos de falas, em língua inglesa, são tomados como recorte. A pesquisa, predominantemente qualitativa, compara as skins no tocante a aspectos visuais e fônicos, bem como observa itens lexicais que remetam ao Brasil. As referências visuais se apresentaram mais complexas (e menos estereotípicas) na primeira skin, ao passo que, na segunda, elementos referentes à produção oral se destacaram. Em ambos os casos, entretanto, houve elementos que sinalizavam para referências a outras culturas.

Palavras-chave: Jogo digital. SMITE. Representações do Brasil. Referências visuais. Fonética e Fonologia. 
V. $11(2)$

$1-24$

maio-ago

2021

Abstract: The present study aims to identify the cultural and linguistic (primarily phonetic-phonological) references to Brazil in SMITE. In this context, the Vamana Cangaceiro and Globeneith skins, as well as their related voice packs in English, constitute the scope. The research, predominantly qualitative, compares the skins with regard to visual and phonic aspects, as well as observes lexical items concerning Brazil. The visual references appeared more complex (and less stereotypical) in the first skin, whilst the ones associated with oral productions stood out in the second skin. In both cases, however, there were elements indicating references to other cultures.

Keywords: Digital game. SMITE. Representations of Brazil. Visual references. Phonetics and Phonology.

\section{Introdução}

O mercado em torno dos jogos digitais tem atingido, mundial e nacionalmente, cifras expressivas. Em 2015, alcançou o posto de segunda maior indústria em faturamento, com uma movimentação de US\$ 4,1 bilhões - estando o Brasil como quinto nesse mercado, contando com 45,2 milhões de pessoas envolvidas nos jogos, conforme Bagatini (2016). A autora, em seu trabalho sobre a cultura gamer no país, observa ainda outros dados relevantes quanto à importância que esses jogos têm assumido socialmente: "jogadores ativos no mundo gastam, somente na Wikipedia, cerca de 100 milhões de horas na construção de conhecimentos coletivos sobre seus jogos favoritos" (BAGATINI, 2016, p. 30).

Dentre os de maior sucesso, está SMITE, lançado em março de 2014 e, em junho do mesmo ano, anunciado com uma versão traduzida para o Brasil. De acordo com uma reportagem do G1, naquele ano, o jogo já se encontrava "[...] entre os três jogos do gênero MOBA (Multiplayer Online Battle Arena) mais populares da atualidade" (GRUPO GLOBO, 2014, online). Atualmente, conta com mais de 20 milhões de jogadores pelo mundo - em informação fornecida pelo perfil oficial do jogo, no Facebook, voltado para o público falante de português. Esse perfil registra mais de 138 mil seguidores, outro número que aponta, de modo mais específico, para a popularidade de SMITE no Brasil.

O país, entretanto, não constitui apenas um mercado consumidor, figurando também como conteúdo para o universo do jogo. Nesse contexto, destacam-se as skins, isto é, as modificações estéticas que também podem afetar o repertório de falas dos personagens (MARCELINO et al., 2017), por referenciarem a cultura brasileira e a língua portuguesa. Apesar disso, o jogo ainda tem sido pouco estudado 
pela comunidade acadêmica, na contramão das crescentes pesquisas acerca de League of Legends, um dos concorrentes de mesmo gênero.

Assim, objetiva-se analisar as referências culturais e linguísticas do Brasil em SMITE, focalizando a produção oral relativa às skins Globeneith e Vamana Cangaceiro. Para tanto, pretende-se (i) investigar as referências culturais por meio dos elementos visuais que compõem as skins, bem como por itens lexicais do português e menções ao país em suas falas e (ii) identificar as marcas de pronúncia típicas de falantes brasileiros quando utilizado o inglês.

Em relação aos elementos visuais, destacam-se, enquanto fundamentação, Araújo (2010), Santos, L. (2012) e Santos, A. (2016). A análise dos conjuntos de falas, por seu turno, está baseada principalmente nas considerações de Shepherd (2001), Kluge (2004), Rauber (2006), Zimmer, Silveira e Alves (2009), Silveira (2011), Lima Jr. (2014), Nascimento (2015), Gutierres (2016) e Souza (2017).

As partes do trabalho foram nomeadas de modo a remeter ao universo de SMITE, incluindo-se subtítulos que pudessem esclarecer o assunto de que trata cada seção. Têm-se, pois, na seção Tutorial, a ambientação para leitores menos familiares ao jogo e, na subseção Minimap, as particularidades que nele estabelecem alguma conexão com o Brasil, para fins de delimitação do corpus. Na seção seguinte, The analysis is about to begin, são apresentados os pressupostos teóricos, enquanto, na seção posterior, Strategy time, é detalhada a metodologia. Já a penúltima seção, The battle begins now, está subdividida em Scratching the surface, para o que diz respeito à análise de elementos visuais, e em Switching the voice pack, sobre os conjuntos de fala. Finalmente, as considerações finais aparecem na seção Conclusões.

\section{Tutorial: conhecendo SMITE}

Johan Huizinga, ainda na década de 1930, ao estudar os jogos de forma ampla, salienta seu caráter de significação para os indivíduos e seu potencial de criação de vínculos sociais. No primeiro capítulo do livro Homo Ludens: o jogo como elemento da cultura, propõe também um conjunto de características formais do jogo, considerando esse como:

[...] uma atividade livre, conscientemente tomada como 'nãoséria' e exterior à vida habitual, mas ao mesmo tempo capaz de absorver o jogador de maneira intensa e total [...] praticada dentro de limites espaciais e temporais próprios, segundo uma certa ordem e certas regras (HUIZINGA, 2007, p.16). 
V. 11 (2)

$1-24$

maio-ago

2021

$\mathrm{Na}$ contemporaneidade, têm-se os jogos digitais, aqueles disponíveis para videogame ou computador, por exemplo, com bastante destaque. É nessa categoria que se insere SMITE, particularmente pertencendo ao gênero MOBA (Multiplayer Online Battle Arena). Este consiste "[...], basicamente, em um jogo de dois times competindo entre si em um mesmo mapa, orientados à cooperação, nos quais cada jogador controla somente um personagem escolhido no início da partida" (AMARAL; MACEDO, 2015, p. 232). Existem diferentes meios e/ou condições específicas para a vitória, incluindo-se a eliminação (kill) de outras divindades. Quando morto, após um período de tempo variável, o personagem ressuscita, de forma que o jogador possa voltar à ação.

Em SMITE, os personagens são seres divinos ou míticos (genericamente referidos como deuses - gods), pertencentes a um de 12 panteões - a saber: celta, chinês, egípcio, grego, hindu, japonês, maia, nórdico, polinésio, romano, eslavo e vodu. O mito dos deuses é explorado na aba história (lore), além de influenciar na concepção das habilidades (skills) de combate. Ao ser selecionado, o deus é bloqueado aos companheiros de time, embora ainda possa aparecer na partida em meio às escolhas adversárias.

Dentre os elementos do jogo, interessam particularmente a esta pesquisa as skins, porque estas têm dado espaço, no universo do jogo, a referências ao Brasil. Cada deus possui, minimamente, uma skin padrão e outras três (Dourada, Lendária e Diamante), em que é modificada apenas a paleta de cores. As demais, que podem variar em número, alteram em maior ou menor proporção a aparência e, opcionalmente, a voz do personagem. Na subseção a seguir, estão elencados elementos concretos em SMITE que se associam ao Brasil.

Minimap: localizando o Brasil

Dos 98 deuses até então lançados, destacam-se dois para os fins desta pesquisa: Vamana e Neith. Aquele, hindu, possui uma skin denominada Cangaceiro, em referência aos cangaceiros nordestinos. Seu traje e armas são modificados, e suas falas ocorrem em língua inglesa, porém com sotaque diferenciado. Essa, egípcia, possui a Globeneith, em referência à Globeleza brasileira. Seu traje é modificado para uma fantasia de carnaval, e suas falas (quotes) ocorrem em língua inglesa, porém com sotaque 
diferenciado e inserção de vocábulos portugueses. Abaixo, apresenta-se uma comparação entre as skins padrão e as supracitadas.

Figura 1 - Comparação entre skins: A: Vamana padrão e Cangaceiro; B: Neith padrão e Globeneith

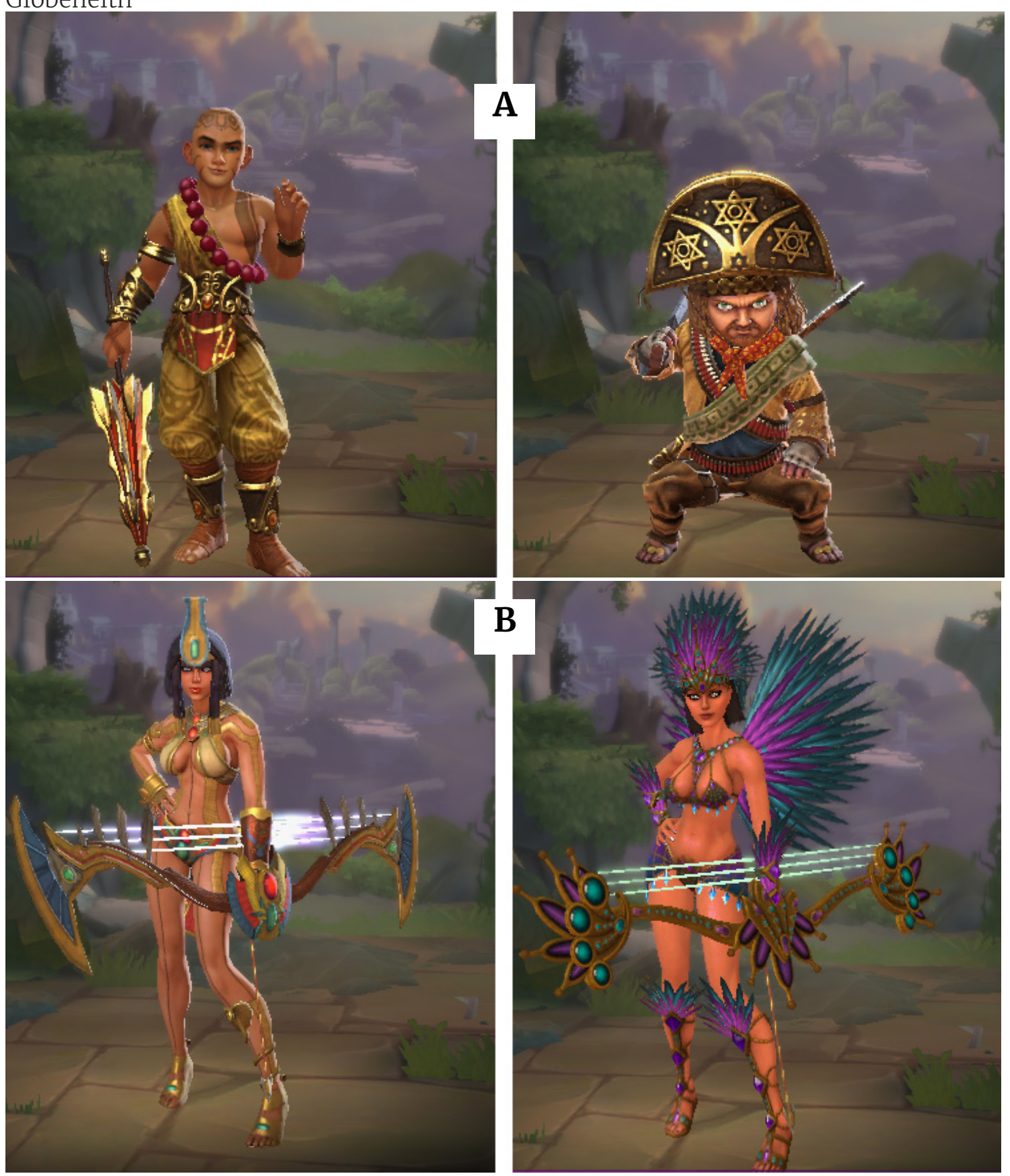

Fonte: captura de tela em SMITE (2019) realizada pelos próprios autores.

Quanto às falas dos personagens, podem-se distinguir dois tipos no que se refere à estrutura e ao conteúdo: um em que são mais livres e outro em que são padronizadas. O primeiro, particular a cada deus, ocorre automaticamente em função de certas condições (início da partida, 
V. $11(2)$

$1-24$

maio-ago

2021

eliminação, contato com deuses específicos etc.), enquanto o segundo é função da ativação de comandos pela combinação de duas a quatro teclas. Tais comandos, materializados em frases curtas, contemplam necessidades da comunicação rápida nas partidas, sinalizando, por exemplo, um pedido de ajuda, um alerta de cuidado ou um local a ser atacado. Por serem comuns a todos os deuses (e às várias skins), constituem material privilegiado para comparar alterações de pronúncia dos personagens, estando disponíveis também em compilações na Wiki do jogo.

Em outros casos encontrados, no entanto, a remissão ao Brasil não é clara. Atena, na skin Amazona, por exemplo, traz, em seu visual e seus diálogos (em língua inglesa), referências à Amazônia, sem estar claro, entretanto, ao território de que país, especificamente. Já Ixibalanque e $\mathrm{Nu}$ Wa, nas skins Estrela do Futebol 2014, e Ace, respectivamente, vestem trajes com as cores verde e amarelo em esportes nos quais o Brasil se destaca (futebol e vôlei). Porém, os pacotes de voz (voice packs) são compartilhados com outras skins, sendo difícil confirmar a alusão ao país e a validade do material linguístico para os fins desta pesquisa.

Há, ainda, um cuidado a ser tomado na análise das skins, decorrente do processo de localização do jogo. A localização "[...] é uma adaptação de um produto ou serviço que atende às necessidades de uma língua e cultura em particular [...]" (SANTOS, 2018, p. 6). Segundo Souza (2014, p. 14), "[...] tem por objetivo proporcionar, da maneira mais próxima possível, a mesma experiência oferecida pela versão original [...]", envolvendo, dentre outras coisas, a tradução de palavras e textos para outros idiomas. Esse objetivo se reflete, por exemplo, em uma das skins de Afrodite, que, na versão em português, chamase Garota de Ipanema, enquanto no original, em inglês, é Beach Babe. Nesse contexto, é preciso consultar o nome das skins ${ }^{1}$ também na versão original, a fim de garantir que foi projetada como referência ao Brasil.

Ademais, cabe ressaltar que a língua portuguesa também aparece na forma oral, manifestando-se na skin Rio Amazonas para o deus He Bo e no locutor de partidas (announcer) em português. Esse, que vem identificado com um ícone da bandeira brasileira, anuncia fatos concernentes ao progresso, em objetivos da partida, e às eliminações de outros personagens.

\footnotetext{
${ }^{1}$ É também por esse motivo - e pela recorrência do uso dos termos em inglês pelo público gamer - que se optou por indicar a equivalência em língua inglesa de algumas palavras ao longo deste trabalho. Isso facilitaria que um leitor familiarizado a consultar a versão original de SMITE identificasse o que está sendo tratado.
} 


\section{The analysis is about to begin: o que saber antes disso}

Retomado o recorte da pesquisa, isto é, a análise do material visual e linguístico relativo às skins Globeneith e Vamana Cangaceiro, são apresentadas, a seguir, as reflexões teóricas necessárias a este trabalho.

Santos, L. (2012) explora, em sua dissertação intitulada "A nacionalidade em jogo: representações do Brasil em jogos digitais", o potencial de representação de determinadas nacionalidades por meio das características atribuídas a personagens, bem como das espacialidades veiculadas. Quanto aos personagens, isso se dá por meio dos imaginários acessados para a construção desses, que podem conter dados geográficos, mas também aspectos ficcionais, de modo que "[...] as primeiras elaborações de jogos digitais já expunham relações de enfrentamento de um Outro, projetando determinadas alteridades a partir de seus contextos de produção" (SANTOS, L., 2012, p. 19).

Em razão disso, este autor ressalta a necessidade de se estender ao campo dos jogos uma postura de problematização, a qual já é adotada em outras áreas de produção simbólica. Voltada às produções estrangeiras, sua pesquisa identifica, em jogos de diversos gêneros, a recorrência de certas representações. Padrões percebidos por Santos, L. (2012, p. 101) são:

o corpo monstruoso, a viabilidade do humano a partir do corpo negro, a visibilidade concedida à cidade do Rio de Janeiro e a delimitação das favelas como territórios cindidos do espaço da cidade e da nação [...].

Além disso, o autor relata um apagamento das diferenças nacionais, bem como o apelo a temporalidades anteriores à modernidade.

Se, por um lado, o carnaval carioca contemporâneo não é estranho a produtos culturais, a referência ao cangaço, por outro, encontra poucas correspondências. Desse modo, para analisar a skin do personagem Vamana, é também importante consultar descrições históricas do movimento.

Muitas vezes considerado um banditismo, percepção que pode ser contestada (CLEMENTE, 2007; SANTOS, 2016), o cangaço foi um movimento no Nordeste brasileiro, com projeção nacional, que contou com diferentes participantes e lideranças. O imaginário a seu respeito, porém, está fortemente associado a uma figura específica, Lampião, que, 
V. $11(2)$

$1-24$

maio-ago

2021 ao contrário [de outros líderes], mesmo sofrendo intensas perseguições de inimigos pessoais e de numerosas forças policiais, decidiu dar visibilidade a si e ao seu bando, por meio de entrevistas e imagens fotográficas (CLEMENTE, 2007, p. 2).

Assim, suas vestimentas e adereços, a serem detalhados durante a análise, constituem um referencial a ser observado na skin.

Desses, Santos (2016, p. 6) destaca o "chapéu meia-lua de couro com uma estrela no meio" como o mais emblemático do cangaceiro, sublinhando sua relevância enquanto símbolo da região ainda na atualidade. Por isso, esse elemento é particularmente descrito na subseção Scratching the surface, buscando-se correspondências de seus componentes em SMITE.

A investigação sobre a produção oral referente a essas skins de SMITE, por seu turno, está centrada no campo da fonética e da fonologia, disciplinas cuja distinção ou interdependência é tema de debate. Enquanto a primeira pode ser entendida como a área que estuda os sons da linguagem com enfoque em aspectos articulatórios, acústicos e perceptivos, a segunda se ocupa da relação entre essas unidades sonoras e de sua diferenciação (CALLOU; LEITE, 2009). As autoras afirmam ainda que

A fonética se distingue, pois, da fonologia pelo fato de considerar os sons independentemente de suas oposições paradigmáticas - aquelas cuja presença ou ausência importa em mudança de significação (CALLOU; LEITE, 2009, p. 11).

Aqui, optou-se por termos como "fonético-fonológico" e "fônico" para expressar um posicionamento conciliador entre as áreas.

Em razão das especificidades de cada idioma, o falante, ao utilizar a segunda língua (L2), está sujeito ao fenômeno da transferência linguística ${ }^{2}$ - conceito tratado por Zimmer, Silveira e Alves (2009) e que se refere à aplicação de conhecimentos de uma língua sobre outra. Na presente pesquisa, interessa sobretudo a transferência fonéticofonológica, na qual "Os novos padrões linguísticos da L2 são percebidos pelo aprendiz de um modo influenciado pelos padrões da L1, os quais estão profundamente enraizados no córtex cerebral do aprendiz" (ZIMMER; SILVEIRA; ALVES, 2009, p. 9, tradução nossa)3. Devido a essa influência da língua materna (L1), o falante pode enfrentar dificuldades para distinguir e produzir sons não comuns a ambos os idiomas.

\footnotetext{
${ }^{2}$ Interlanguage transfer.
}

3 "The new linguistic patterns of L2 are perceived by the learner in a way which is biased towards the L1 patterns, which are deeply entrenched in the learner's cerebral cortex". 
É nesse contexto que pode ser enquadrada a situação dos personagens Neith e Vamana - quando utilizadas as skins Globeneith e Cangaceiro, tratando-se de falantes brasileiros que têm o inglês como L2. Assim, cabe consultar bibliografia relacionada à influência do português brasileiro na realização da língua inglesa - sobre a qual discorremos a seguir.

Em relação aos sons vocálicos, há uma maior quantidade no inglês - 14, contra 7 tônicas do português brasileiro (NASCIMENTO, 2015). De acordo com a autora, o aprendiz de língua inglesa enfrenta dificuldades para diferenciar fonemas semelhantes cuja distinção não existe na L1, podendo, com isso, perceber como variantes de pronúncia aquilo que são fonemas e palavras contrastantes. Exemplos disso são os pares de vogais tensas e frouxas, como /i:-1/ ou /u:- $/$ /. As distinções entre os sons vocálicos dessas línguas abrangem pistas como duração, tensão, altura e posteridade, o que ocasiona produções alternativas (LIMA JR, 2014; RAUBER, 2006).

Semelhantemente, há também um maior inventário no inglês em relação aos sons consonantais. Um dos casos mais notáveis está relacionado aos sons representados pelos grafemas $\mathrm{TH}$, / $\theta$ / e /ð/, muitas vezes realizados como [s] e [z], [t] e [d] ou mesmo [f] e [v] (SHEPHERD, 2001). Ocorre também a substituição entre /t/, em caso de flap 4 , e /r/, o que motiva confusão entre as palavras better e bearer, como exemplifica Shepherd (2001, p. 115). Quando em posição inicial, alguns fonemas do inglês $(/ \mathrm{p} /, / \mathrm{k} / \mathrm{e} / \mathrm{t} /)$, quando produzidos por brasileiros, podem ter realização fonética semelhante a outros da língua-alvo (respectivamente /b/, /g/ e /d/), em razão de o português brasileiro não possuir o padrão de aspiração (ALVES, 2008). Já em posição final, alguns casos que chamam a atenção são a omissão de /m/, /n/ e /n/ em favor da simples nasalização da vogal anterior (KLUGE, 2004; GUTIERRES, 2016), e a troca do /l/ por uma vogal próxima ao [ซ] (SHEPHERD, 2001). Essas substituições ocorrem de modo a aproximar a L2 da estrutura da L1.

O caso da omissão das consoantes nasais, por sua vez, também está relacionado ao fato de as construções silábicas permitidas em cada idioma serem distintas: em português, são menos frequentes as situações em que uma sílaba se encerre por consoante (SHEPHERD, 2001, p. 116, tradução nossa)5. Além disso, "a variedade de encontros consonantais

\footnotetext{
4 "Tipo de vibrante realizada com um único contato momentâneo da ponta da língua contra o alvéolo [r]. Ex.: em português, 'cara'; em inglês, 'item'." (LAMPRECHT, 2009, p. 345)

5 "Few consonants can occur finally in Portuguese, and so a vowel is often added: 'parkie' for park; 'cabbie' for cab.". Sobre padrões silábicos, ver Silveira (2011).
} 
V. $11(2)$

1-24

maio-ago

2021

é muito maior em inglês do que em português" (SHEPHERD, 2001, p. 116, tradução nossa) ${ }^{6}$, o que pode conduzir à simplificação desses encontros e/ou à epêntese, ou seja, à inserção de vogais - enfoque da dissertação de Nascimento (2015). Como consequência desse fenômeno, uma palavra inglesa produzida por um brasileiro pode soar como seu diminutivo, a exemplo de cutie (fofinho) em lugar de cute (fofo).

Shepherd (2001) e Zimmer, Silveira e Alves (2009) acrescentam que falantes brasileiros muitas vezes realizam produções alternativas ao padrão de acentuação (stress), seja de vocábulos tomados isoladamente ou em sentenças. Concordam também que, no que tange à escrita, a relação grafo-fônico-fonológica, ou seja, a correspondência entre letras e sons, é mais opaca na língua inglesa, fazendo com que falantes do português, influenciados pela ortografia das palavras, adotem pronúncias diferentes do esperado.

Cabe ressaltar, ainda, que ao tratar de questões linguísticas, mesmo que o foco seja apenas fonético-fonológico, é necessário considerar o caráter dinâmico, heterogêneo e evolutivo de todas as línguas vivas, as quais variam de acordo com fatores de ordem histórica, geográfica, social e contextual (ALKMIN, 2001).

A variação é uma parte inerente a todas as línguas (LABOV, 1969) e pode ser entendida como duas ou mais formas de dizer a mesma coisa com o mesmo valor referencial; ela "não compromete o bom funcionamento do sistema linguístico nem a possibilidade de comunicação entre os falantes" (COELHO et al., 2015, p. 16). A variação linguística ocorre em níveis distintos (lexical, fonético-fonológico, semântico, morfossintático e pragmático-estilístico) e é, também, bastante comum entre aprendizes de línguas, que tendem a variar entre formas padrão da língua-alvo e formas que deixam clara a influência da língua materna. Esse processo é natural e até esperado entre indivíduos que estão adquirindo uma língua estrangeira.

Assim, ao propor como um de seus objetivos identificar as marcas de pronúncia comuns a falantes brasileiros quando se comunicam em inglês, esta pesquisa não pode ignorar o fenômeno da variação linguística, uma vez que aqueles falantes podem utilizar variantes da língua-alvo ou mesmo serem influenciados por variantes de sua própria língua materna ao pronunciarem palavras em inglês.

\footnotetext{
6 "The range of consonant clusters is much wider in English than in Portuguese".
} 


\section{Strategy time: pressupostos metodológicos}

Adotou-se uma metodologia de cunho qualitativo, com a análise estruturada em duas partes: uma destinada aos elementos visuais e outra aos conjuntos de falas - em ambos os casos, agrupandose os dados de acordo com as skins às quais se referem. Na primeira, são descritos os elementos que compõem a aparência de cada skin, observando-se em que medida referenciam a cultura nacional e a sua relação a certos estereótipos. Já na segunda, são identificadas as marcas de pronúncia típicas de falantes brasileiros e, em seguida, o emprego de itens lexicais do português e as eventuais menções ao país.

Para tanto, optou-se pelo uso das compilações da Wiki ${ }^{7}$ enquanto mecanismo de apoio, em razão de permitirem o acesso pontual a cada fala (nas versões escrita e sonora), sem interferência dos demais efeitos visuais e sonoros do jogo. Cada skin dispõe de 193 falas compiladas e submetidas à análise em sua totalidade - porém selecionadas para exemplificação e/ou transcrição fonética - apenas por meio da oitiva dos autores, pois é esperado que a referencialidade ao Brasil seja reconhecível por jogadores durante as partidas. A influência do português brasileiro foi identificada a partir de 7 marcas, registradas por quantidade de ocorrências, a saber: i) transferência grafo-fonéticofonológica na produção vocálica; ii) epêntese vocálica; iii) omissão de consoantes nasais; iv) produção de [w] em lugar de /l/; v) produção de [r] em lugar de /t/; vi) não aspiração de /p/, /k/ ou /t/; e vii) TH produzido como $[\mathrm{s}],[\mathrm{t}],[\mathrm{z}]$ ou $[\mathrm{d}]$.

\section{The battle begins now: análise}

A análise das skins foi dividida em duas seções: uma dedicada aos elementos visuais e outra aos conjuntos de falas.

Scratching the surface: elementos visuais das skins

Retomemos a figura 1. Em A, à direita, tem-se a caracterização da skin por uma indumentária complexa, composta de diversos itens que se sobrepõem parcialmente em camadas. Destacam-se, dentre eles, o grande chapéu decorado com estrelas, as armas - um sabre com inscrições na lâmina e uma arma de fogo semelhante a uma espingarda.

7 Disponível nos links https://smite.gamepedia.com/Carnaval_Queen_Neith_voicelines e https://smite.gamepedia.com/Cangaceiro_Vamana_voicelines, acesso em 08 jul. 2019. 
V. $11(2)$

$1-24$

maio-ago

2021

Além disso, vê-se munição disposta em cartucheiras ao redor do tronco do personagem e um lenço no pescoço.

"Sem dúvida o elemento mais representativo e icônico do cangaço é o chapéu" (SANTOS, 2016, p. 6) e, por isso, cabe uma explicação com mais detalhes. Fabricado em couro e no formato de meia-lua, o chapéu tinha a aba dobrada para trás a fim de não prejudicar a visão do cangaceiro. Era decorado com fitas de couro nas laterais, enquanto, na frente, acrescentavam-se joias, moedas e a estrela de Davi - com a qual se pretendia também alcançar proteções no campo místico/espiritual. Araújo (2010) elenca ainda possíveis ligações simbólicas entre o chapéu dos cangaceiros com o de Napoleão e/ou coroas reais. No que se refere a SMITE, esse item apresenta, pois, uma caracterização bastante completa e fiel aos dados históricos.

Quanto aos atributos físicos, como a barba e os cabelos relativamente compridos - no nível dos ombros, em especial contraste com a skin padrão -, não há, na bibliografia consultada, menção de que esses fossem ou não emblemáticos entre cangaceiros. Quanto às diferenças nas feições e na estatura, é importante ressaltar que o deus passou por remodelagem em momento posterior ao lançamento da skin de Cangaceiro, distanciando-se da versão original em certas características. Comparando-se à descrição do icônico Lampião, resgatada de arquivos históricos por Clemente (2007), não há muitas correspondências: tinha estatura mediana, pele escura e cabelos fartos, porém pretos.

Há ainda aspectos talvez menos conhecidos dos trajes de cangaceiros, como ressalta Araújo (2010, p. 3): "faixas e bornais com bordados coloridos" e o "fardamento azul acinzentado", os quais podem ser identificados na skin do jogo. A vestimenta se caracterizava ainda pelo uso de alpargatas nos pés e incluía luvas e perneiras para proteção no ambiente da caatinga (SANTOS, 2016).

Assim, percebe-se que a composição da skin em questão envolveu originalidade (pela escolha de elementos pouco explorados da cultura brasileira) e busca por verossimilhança a partir de dados históricos, apresentando considerável atenção a detalhes. As marcas no sabre e a caracterização física, entretanto, apontam para certa liberdade criativa dos desenvolvedores do jogo, uma vez que não foram encontradas referências a isso na literatura consultada.

Já a skin Globeneith, à direita na figura 1B, configura, neste âmbito, um menor desafio à análise, visto que se assemelha a fantasias 
existentes em desfiles de escolas de samba contemporâneos. O traje, por expor a maior parte do corpo da deusa e ter os adereços - particularmente plumagens - concentrados na parte superior, remete à figura das rainhas de bateria. Corrobora a construção dessa referência ao carnaval o nome da skin, baseado no título de Globeleza das musas, cuja imagem é associada à cobertura dessa época do ano pela Rede Globo.

A vinculação entre skin e deusa, em específico, pode ter sido motivada pela tonalidade de pele e vestimentas originais de Neith (na figura, à esquerda). Neith, como uma das poucas deusas de pele negra lançadas à época, podia espelhar a maioria da população brasileira - 55,8\% que se declara negra ${ }^{8}$. Ademais, é a imagem da mulher negra ("mulata") a mais associada ao Carnaval. O traje original da personagem, por sua vez, já expunha consideravelmente o corpo e incluía sapatos de salto, o que se alinha às fantasias de rainha de bateria dentre os demais tipos existentes. De modo geral, o que se constata é um apelo ao estereotípico, em contraposição ao caso da outra skin observada.

Cabe ponderar, ainda, a respeito da sexualização do corpo feminino na personagem em questão. Abreu e Pereira (2018, p. 694) entendem os jogos eletrônicos como "[...] artefatos da cultura visual e, portanto, fenômenos culturais capazes de contribuir para a formação dos modos de ser e agir de um indivíduo". Dessa forma, a exposição aqui mencionada pode reforçar mentalidades de erotização da mulher, especialmente da mulher negra. Em seu trabalho, os autores identificam a representação feminina predominante em SMITE como de "[...] uma mulher fruto de um padrão estético criado a partir de um olhar de apreciação masculina - demonstrado nos seios exagerados, cinturas extremamente afiladas, [...] e posições e roupas sensuais" (ABREU; PEREIRA, 2018, p. 700). Os autores também questionam que, em se tratando de um jogo de combate corpo a corpo, "[...] é difícil pensar que as personagens femininas tem [sic] que lutar com essas vestimentas" (ABREU; PEREIRA, 2018, p. 700). Em se tratando de uma referência ao Brasil, a skin Globeneith pode, ainda, fortalecer discursos de que as brasileiras seriam "fáceis".

8 Dados do IBGE disponíveis em https://noticias.uol.com.br/cotidiano/ultimasnoticias/2019/05/22/ibge-em-todas-as-regioes-mais-brasileiros-se-declaram-pretos.htm e acessados em 24 jun. 2019. 
V. $11(2)$

$1-24$

maio-ago

2021

Switching the voicepack: conjuntos de falas das skins

Na skin Vamana Cangaceiro, contrariamente ao observado visualmente, foram constatadas poucas das marcas de influência do português brasileiro. Dentre as 193 falas, houve apenas 4 ocorrências de marcas da pronúncia brasileira definidas a partir da literatura consultada, como detalha o gráfico a seguir:

\section{Gráfico 1 - Análise do conjunto de falas da skin Vamana Cangaceiro}

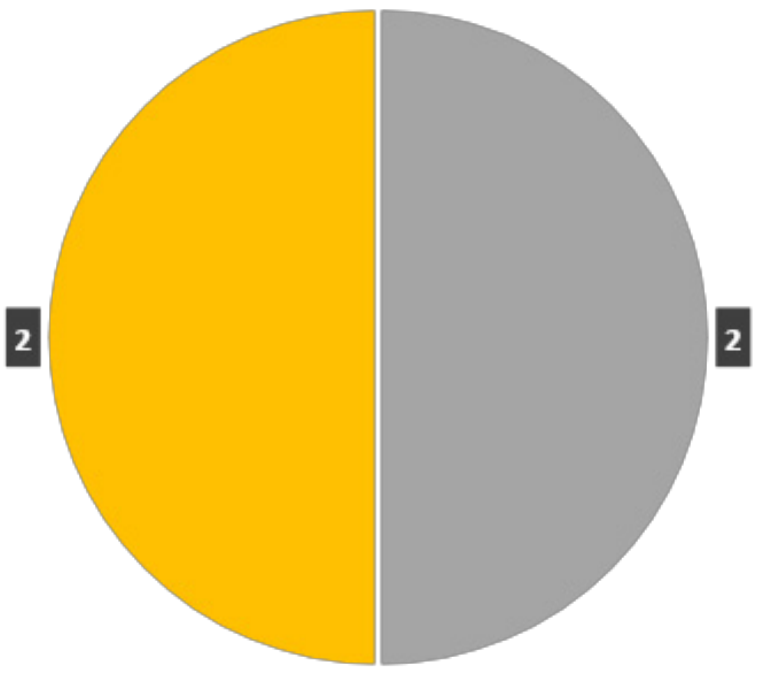

Transferência grafo-fonético-
fonológica na produção
vocálica
Epêntese vocálica
Omissão de consoantes nasais
[w] em lugar de ///
[s] em lugar de $/ z /$
[r] em lugar de /t/
Não aspiração de $/ p /, / k /$ ou $/ t /$
TH produzido como [s], [z], [t]
ou [d]

Fonte: dados ${ }^{9}$ da pesquisa - classificação feita com base na discussão apresentada na seção The analysis is about to begin.

Quanto à omissão de consoantes nasais, houve ocorrências em "Fantastic!" e "On my way!". No entanto, não se trata de um padrão na pronúncia do fonema /n/ - que é realizado em outras falas. A exemplo disso, em "I don't plan on dying today!", /n/ ocorre de forma clara.

Semelhantemente, não é estabelecido um padrão em termos da substituição da consoante /l/ pela semivogal [w], fenômeno descrito por Souza (2017) e Shepherd (2001). Enquanto foram identificadas ocorrências em "The Volantes will never catch me alive!" e "Cancel that!", há também exemplos de clara pronúncia do fonema /1/, como em "They'll never take me alive!" e "Take this jungle buff.". Entendese, porém, que essa variabilidade é natural na fala de aprendizes de línguas, os quais alternam frequentemente entre os padrões da línguaalvo e os da sua língua materna, o que não constitui um problema, mas uma característica do processo de aprendizagem.

\footnotetext{
9 Identificação realizada apenas a partir da oitiva dos autores, pois é esperado que a referencialidade ao Brasil seja reconhecível por jogadores.
} 
É comum, pois, nas ocorrências analisadas, certa inconsistência na pronúncia, que poderia ser explicada em razão das condições de gravação e/ou de ativação das falas ou, ainda, em função de o ator que dubla a skin não ser nativo de língua inglesa ${ }^{10}$. Outra possibilidade, como comentado acima, é de que a variação na performance pretenda contemplar a variabilidade da fala de aprendizes de língua estrangeira.

Já quanto a itens lexicais da língua portuguesa e referências ao Brasil, não foram encontradas muitas ocorrências. É importante salientar, nesse quesito, a presença de "Volantes" (em exemplo supracitado): o termo pode se tratar de empréstimo do português, referindo-se às tropas ligadas ao governo, cujo objetivo era combater o cangaço. A pronúncia da palavra, porém, se aproxima bastante do espanhol, com o V inicial soando como uma fricativa bilabial sonora e não havendo a típica pronúncia do E enquanto [i] ${ }^{11}$. Em função de variações fonéticas como essa, fica prejudicada a relação entre skin e cultura/nação referenciada.

Por fim, é importante destacar que houve um conjunto de falas completamente em português para Vamana Cangaceiro, dublado por Tadeu Mello' ${ }^{12}$ - nascido no Ceará e reconhecido por personagens nordestinos. A razão da opção pela dublagem corrente, contudo, não é clara.

Na skin Globeneith, por seu turno, foi constatada uma maior quantidade de marcas da influência do português brasileiro. Dentre as 193 falas, em pelo menos 48 houve ocorrências relativas a algum(ns) dos 7 aspectos - como detalhado no gráfico (e no apêndice A):

\footnotetext{
${ }^{10}$ Para a skin Vamana Cangaceiro, o ator de voz foi Kaiji Tang, de origem chinesa e baseado nos Estados Unidos. A skin padrão do deus tem a dublagem de Sean Chiplock, nascido nos Estados Unidos.

${ }_{11}$ Apesar de ser comum a produção da vogal átona E como [i] na região nordeste do Brasil, onde o personagem cangaceiro estaria ambientado, alguns dialetos de outras regiões do país realizam essa produção como [e].

${ }^{12}$ Informação divulgada em https://tvuol.uol.com.br/video/dublagem-de-vamana-cangaceironova-skin-para-smite-04028C18376EC4A15326 (acesso em: 10 jul. 2019). No link, as falas do personagem aparecem no vídeo.
} 
V. $11(2)$

$1-24$ maio-ago 2021
Gráfico 2 - Análise do conjunto de falas da skin Globeneith

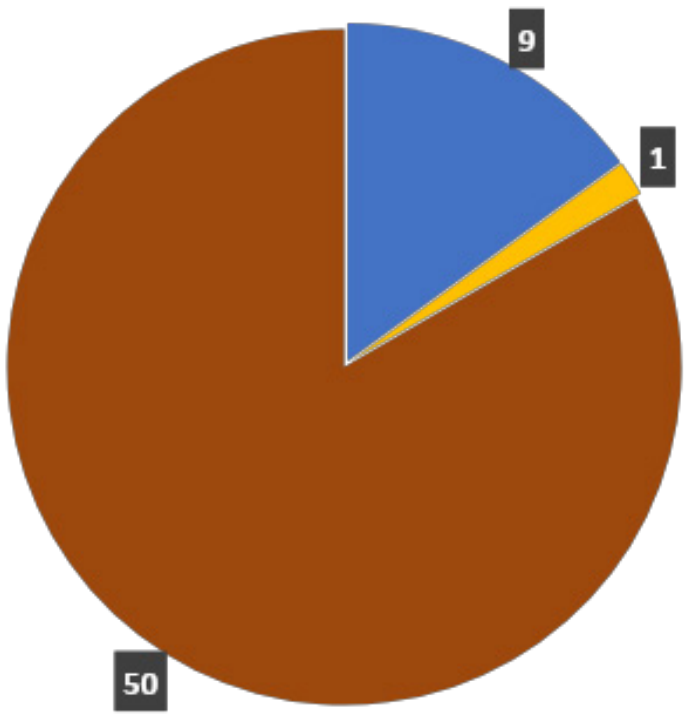

Transferência grafo-fonético-

fonológica na produção

vocálica

Epêntese vocálica

Omissão de consoantes nasais

[w] em lugar de /I/

[s] em lugar de $/ z /$

[r] em lugar de /t/

Não aspiração de $/ \mathrm{p} /, / \mathrm{k} / \mathrm{ou} / \mathrm{t} /$

TH produzido como [s], [z], [t]

ou [d]

Fonte: dados ${ }^{13}$ da pesquisa - classificação feita com base na discussão apresentada na seção The analysis is about to begin.

A produção alternativa do TH - isto é, dos sons correspondentes aos fonemas /ð/ e / / $/$ - não somente constitui a marca de maior recorrência como também apresentou considerável regularidade. Grande parte das ocorrências de TH sofreram alguma mudança, tendo sido os sons realizados primordialmente como [d]. Em "It is time for the biggest party in the world! Carnival!", por exemplo, ambos os artigos definidos (the) sofrem a alteração para $[d ə]^{14}$. Além disso, houve casos menos frequentes em que TH foi produzido como [z] ("You can't stop the rhythm in my heart!") e [t] ("That was unlucky"). Foram constatados ainda casos de substituição por [s], dentre os quais se destaca "I think I've seen someone in a costume like yours!".

O fonema /t/ teve a pronúncia marcada por variação, o que é comum também para falantes nativos de inglês americano. A exemplo disso, a consoante foi realizada tanto enquanto [t] (como em "The party is about to start!") como pode se aproximar do flap ("I'm bringing the party to you!"). Quanto ao fonema /l/, observou-se um único registro de substituição por [w]: "I'll Attack right lane!".

${ }_{13}$ Identificação realizada apenas a partir da oitiva dos autores, pois é esperado que a referencialidade ao Brasil seja reconhecível por jogadores.

${ }_{14}$ Cabe mencionar que essa realização não é exclusiva de falantes brasileiros, podendo ocorrer inclusive na fala de nativos do inglês. Um exemplo disso é o African American Vernacular English, variante comum a afro-americanos nos Estados Unidos, em que "/ $/$ / is often replaced with /d/, /.d/, or [v]" (THOMAS, 2007, p. 454). 
Já a transferência grafo-fonético-fonológica na produção vocálica ocorreu em circunstâncias consideravelmente distintas. Ou seja, houve diferentes casos em que a pronúncia de vogais sofreu alteração, aproximando-se do repertório do português brasileiro: um dos que se repetiu, por exemplo, está expresso em "Enemy ultimate down!": havendo as substituições, respectivamente, de / $/$ por [ $\mho]$.

Similarmente à skin anterior, casos de variação na pronúncia poderiam ter motivação nas condições de gravação e/ou de ativação das falas ou, ainda, na influência da língua nativa da atriz ${ }^{15}$ que dubla a skin, bem como na pretensão de contemplar a variabilidade na fala de aprendizes de língua estrangeira.

Já quanto ao conteúdo, as falas da skin Globeneith apresentam constantes referências ao Carnaval (na forma em inglês ${ }^{16}$, "Carnival", com 3 ocorrências) e ao samba (em pronúncia estrangeira, com 4 ocorrências). Uma dessas quatro se destaca por ser parte de um neologismo, em "You try samba-ing "til the crack of dawn in these heels!". Outra referência ao universo da dança é a palavra "tango" (em "Do not tango with my affairs, darling!"), o que desloca parcialmente a referencialidade para culturas hispânicas.

Nesse contexto, talvez as referências mais explícitas ao Brasil estejam em: "Copa, Copacabana!" e "They say Rio is the best place to fall in love... With dancing!". Na primeira, aparecem as palavras "Copa" e "Copacabana"17, além de que "Rio", no segundo exemplo, é pronunciado com a consoante R presente no português brasileiro.

\section{Conclusões}

O presente trabalho investigou, portanto, referências ao Brasil estabelecidas em SMITE, um jogo digital de grande relevância

\footnotetext{
${ }^{15}$ Não foi possível confirmar a nacionalidade e/ou língua materna da atriz de voz para a skin Globeneith. No perfil de uma rede social https://www.linkedin.com/in/valeria-zunzun761a7a11, Valeria Zunzun se apresenta como "Trilingual voice talent and actress" e associa a palavra nativo (native) às línguas espanhola e francesa. Ela destaca, ainda, ter experiência de trabalho com o português.

${ }^{16}$ Contrariamente ao que ocorre nas falas, o nome da skin, quando, na versão em língua inglesa, vale-se de um empréstimo linguístico. Assim, o léxico do português se combina à sintaxe inglesa para formar "Carnaval Queen" (Rainha do Carnaval).

${ }^{17}$ Dado o tema "Carnaval" da personagem e a menção a "Rio", as palavras "Copa" e "Copacabana" provavelmente se referem à famosa praia do Rio de Janeiro. Outras referências possíveis para "Copa" poderiam ser ao campeonato mundial de futebol, esporte pelo qual o país é conhecido, e/ ou a uma boate em Nova York - mencionada em uma canção de 1970. Para saber mais da música, sugerimos o link https://www.songfacts.com/facts/barry-manilow/copacabana-at-the-copa.
} 
V. $11(2)$

$1-24$

maio-ago

2021

no mercado geral e, mais especificamente, dentro do gênero MOBA. Quanto ao corpus selecionado, isto é, os elementos visuais e os conjuntos de falas vinculados às skins Vamana Cangaceiro e Globeneith, foram identificados tanto elementos estereotípicos quanto caracterizações mais aprofundadas na história e na cultura do país.

No âmbito visual, percebeu-se uma referenciação cultural bastante rica (em quantidade de elementos e detalhamento) e bastante comprometida com a acurácia histórica em relação ao cangaço. Assim, a skin para o deus Vamana traz visibilidade a uma figura brasileira menos midiatizada, sobretudo internacionalmente: a do cangaceiro. Em Globeneith, contrariamente, prevalece o apelo ao estereótipo de Carnaval pautado nos desfiles de escolas de samba e rainhas de bateria. Pela exposição da personagem, a skin suscita questões sobre a sexualização do corpo feminino. Nas falas, houve poucas menções explícitas à cultura nacional, bem como poucos empréstimos linguísticos do português. Ademais, a presença de elementos relativos a culturas hispânicas compromete a percepção da referencialidade proposta.

Já em âmbito fônico, quase não há, em Vamana Cangaceiro, marcas da pronúncia típica brasileira. Nesse quesito, o inglês utilizado em Globeneith apresenta maior variedade e número de ocorrências das marcas observadas - sobretudo no que diz respeito à pronúncia do TH. Em ambos os conjuntos de fala, entretanto, foi percebida certa inconstância na forma como fonemas e palavras eram realizadas. Em relação a isso, convém retomar o debate sobre variação linguística: tanto o português brasileiro e o inglês possuem variantes - havendo diferentes possibilidades de referência a essas línguas -, quanto o processo de aprendizagem de uma língua é caracterizado pela variação na fala do indivíduo. Sob essa perspectiva, seria possível enxergar tais inconstâncias também como referências a um falante não nativo de inglês.

A partir da posição de professores de língua, com habilitação em português e inglês, enxergamos aplicações ao ensino para ambas as skins. O contato com esses conjuntos de falas (no universo lúdico do jogo) favoreceria, pois, que estudantes de inglês como segunda língua percebessem traços do próprio sotaque. Isso permitiria trabalhar a aceitação de uma pronúncia não nativa, bem como chamar a atenção para questões fonético-fonológicas importantes a esse público e pautar debates em torno das variações de pronúncia observadas.

Por fim, as possibilidades de estudo do jogo não se encerram nesta pesquisa, havendo outras referências ao país já existentes, como 
elencado na subseção Minimap. Além disso, novas referências podem surgir na medida em que SMITE seja atualizado.

\section{Referências}

ABREU, C. L.; PEREIRA, C. E. S.. Cultura visual, gênero e poder: a estereotipação do corpo feminino no jogo SMITE. In: II Seminário Internacional de Pesquisa em Arte e Cultura Visual, 2018, Goiânia. Anais... Goiânia: Universidade Federal de Goiás, 2018. p. 692-702. Disponível em: <https://seminarioculturavisual. fav.ufg.br/up/778/0/LC_CESAR_PEREIRA_CARLA_ABREU_IISIPACV2018. pdf $>$. Acesso em: 30 ago. 2019.

ALKMIN, T. M. Sociolinguística: parte 1. In: MUSSALIN, F.; BENTES, A. C. (orgs.). Introdução à linguística: domínios e fronteiras. São Paulo: Cortez, 2001. v. 1. p. 1-47.

ALVES, U. K. A aquisição das sequências finais de obstruintes do inglês (L2) por falantes do sul do Brasil: análise via teoria da otimidade. 2008. Tese (Doutorado em Letras) - Faculdade de Letras, Pontifícia Universidade Católica do Rio Grande do Sul, Porto Alegre, 2008. Disponível em: $<$ https://tede2.pucrs. br/tede2/bitstream/tede/1835/1/399693.pdf >. Acesso em: 19 set. 2020.

ARAÚJO, G. G. Aparição do cangaceiro. In: VI ENECULT, Salvador, 2010. Anais... Salvador: Centro de Estudos Multidisciplinares em Cultura, 2010. n.p. Disponível em: <http://www.cult.ufba.br/wordpress/24525.pdf>. Acesso em: 02 mar. 2019.

BAGATINI, J. Epic Win: análise da cultura gamer no Brasil: a consolidação das marcas no universo fantástico dos jogos eletrônicos. Santa Cruz do Sul: UNISC, 2016, 86p. Disponível em: <http://hdl.handle.net/11624/2092>. Acesso em: 24 dez. 2018.

CALLOU, D.; LEITE, Y. Iniciação à fonética e à fonologia. 11. ed. Rio de Janeiro: Jorge Zahar, 2009. Disponível em: < [https://books.google.com.br/ books?hl=pt-BR\&lr=\&id=lO14f6VxYxoC\&oi=fnd\&pg=PP1\&dq=fon\%C3\%A9tica + +e+fonologia\&ots=agTeHxW7Gv\&sig=xQYmhNdR86p4VnXTRzA8S6HTqEW\#v =onepage\&q=nema\&f=false $>$. Acesso em: 12 mar. 2019.

CLEMENTE, M. E. A. Cangaço e cangaceiros: histórias e imagens fotográficas do tempo de Lampião. Fênix - Revista de História e Estudos Culturais, Uberlândia, v. 4, n. 4, p. 1-18, out./nov./dez. 2007. Disponível em: <http:// www.revistafenix.pro.br/PDF13/DOSSIE \%20ARTIGO_13-Marcos_Edilson_ de_Araujo_Clemente.pdf $>$. Acesso em: 24 mai. 2019.

COELHO, I. L.; SOUZA, C. M. N. de; GÖRSKI, E. M.; MAY, G. H. Para conhecer sociolinguística. São Paulo: Contexto, 2015.

GRUPO GLOBO. GAME de batalha em arenas 'Smite' chega traduzido ao Brasil. G1, São Paulo, 06 jun. 2014. Tecnologia e Games. Disponível em: <http:// g1.globo.com/tecnologia/games/noticia/2014/06/game-de-batalha-emarenas-smite-chega-traduzido-ao-brasil.html >. Acesso em: 25 dez. 2018.

GUTIERRES, A. Variação na aquisição fonológica: análise da produção da nasal velar em inglês (L2). 2016. Tese (Doutorado em Letras) - Programa de Pós-Graduação em Letras, Universidade Federal do Rio Grande do Sul, Porto 
V. $11(2)$

$1-24$

maio-ago

2021

Alegre, 2016. Disponível em: <https://lume.ufrgs.br/handle/10183/142958>. Acesso em: 19 set. 2020.

HUIZINGA, J. Natureza e Significado do Jogo como Fenômeno Cultural. In: HUIZINGA, J. Homo Ludens: o jogo como elemento da cultura. Tradução João Paulo Monteiro. São Paulo: Perspectiva, 2007, cap. 1. p. 3-31. Disponível em: <https://edisciplinas.usp.br/pluginfile.php/4184246/mod_resource/ content/o/homo ludens huizinga.pdf $>$. Acesso em: 07 mar. 2019.

KLUGE, D. C. Perception and production of English syllable-final nasals by Brazilian learners. 2004. Dissertação (Mestrado em Letras/Inglês e Literatura Correspondente) - Centro de Comunicação e Expressão, Universidade Federal de Santa Catarina, Santa Catarina, 2004. Disponível em: <https:// repositorio.ufsc.br/xmlui/bitstream/handle/ 123456789/87658/212390. pdf? sequence $=1 \&$ isAllowed $=\mathrm{y}>$. Acesso em: 18 set. 2020.

LABOV, W. Contraction, deletion and inherent variability of the English copula. Language, v. 45, n. 04, p. 715-762, 1969.

LAMPRECHT, R. R. Glossário. In: LAMPRECHT, R. Consciência dos sons da língua: subsídios teóricos e práticos para alfabetizadores, fonoaudiólogos e professores de língua inglesa. Porto Alegre: EDIPUCRS, 2009, p. 341-352. Disponível em: <https://books.google.com.br/books?id=40cyKLIIh/8C\&pg=P A $345 \& d q=0+q u e+\% C 3 \% A 9+0+F L A P+e m+f o n \% C 3 \% A q t i c a+d e+1 \% C 3 \% A d n g u$ a +inglesa\&hl =pt $-\mathrm{BR} \& \mathrm{sa}=\mathrm{X} \& \mathrm{ved}=0$ ahUKEwiZrrH7orPmAhVcIbkGHWxJAooQ 6AEIKTAA\#v=onepage\&q=0\%20que $\% 20 \% C 3 \% A 9 \% 200 \% 20 F L A P \% 20$ em $\% 20$ fon $\%$ C $3 \%$ Agtica $\% 20$ de $\% 201 \%$ C3\%Adngua\%20inglesa\&f=false $>$. Acesso em: 10 jan. 2020.

LIMA JR., R. Padrões de duração de seis vogais do inglês produzidas por alunos brasileiros. Estudos da Lingua(gem), Vitória da Conquista, v. 12, n. 2, p. 13-30, dez. 2014. Disponível em: <http://periodicos2.uesb.br/index.php/ estudosdalinguagem/article/view/1251>. Acesso em: 23 set. 2020.

MARCELINO, R. M. A.; MORAES, I.; RAMOS, C. M.; SATO, S. K.; SILVEIRA, R. A. O consumo in-game: Uma análise comparativa de duas modalidades de compra em MMOs. In: 40 CONGRESSO BRASILEIRO DE CIÊNCIAS DA COMUNICAÇÃO, 2017, Curitiba. Anais... São Paulo: Intercom. Disponível em: $<$ http://portalintercom.org.br/anais/nacional2017/resumos/R12-0281-1.pdf>. Acesso em: 24 dez. 2018.

NASCIMENTO, G. C. A. Epêntese vocálica em encontros consonantais por falantes brasileiros de inglês como língua estrangeira. 2015. 151f. Dissertação (Mestrado em Linguística e Língua Portuguesa). Faculdade de Ciências e Letras, Universidade Estadual Paulista, Araraquara. Disponível em: <https://repositorio.unesp.br/bitstream/handle/11449/126528/000840772. pdfsequence $=1 \&$ isAllowed $=\mathrm{y}>$. Acesso em: 12 mar. 2019.

RAUBER, A. S. Perception and production of English vowels by Brazilian EFL speakers. 2006. Tese (Doutorado em Letras/Inglês e Literatura Correspondente), Centro de Comunicação e Expressão, Universidade Federal de Santa Catarina, Santa Catarina, 2006.

SANTOS, A. L. S. O irredentismo no nordeste demonstrado no chapéu do cangaceiro. In: V CONGRESSO SERGIPANO DE HISTÓRIA E V ENCONTRO ESTADUAL DE HISTÓRIA DA ANPUH/SE, Aracajú, 2016. Anais... Aracajú: 
Associação Nacional de História, out. 2016. Disponível em: <http://www. encontro2016.se.anpuh.org/resources/anais/53/1486558951 ARQUIVO OIRREDENTISMONONORDESTEDEMONSTRADONOCHAPEUDOCANGACEIRO. pdf >. Acesso em: 02 mar. 2019.

SANTOS, J. P. Q. SMITE: Tradução e Localização: apropriação cultural dentro do mundo dos videojogos. 2018. 92 f. Dissertação (Mestrado em Tradução e Interpretação Especializadas) - Instituto Superior de Contabilidade e Administração do Porto, Instituto Politécnico do Porto, Porto (Portugal), 2018. Disponível em: <https://recipp.ipp.pt/bitstream/10400.22/12999/1/ Jo\%c3\%a30_Santos_MTIE_2017.pdf>. Acesso em: 30 ago. 2019.

SANTOS, L. V. V. A nacionalidade em jogo: representações do Brasil em jogos digitais. 2012. $141 \mathrm{f}$. Dissertação (Mestrado em Cultura e Sociedade). Instituto de Humanidades, Artes e Ciências, Universidade Federal da Bahia, Salvador, 2012. Disponível em: <https://repositorio.ufba.br/ri/bitstream/ ri/16633/1/Disserta\%C3\%A7\%C3\%A30\%20de\%20Leandro\%20Viana\%20 Villa\%20dos\%20Santos.pdf>. Acesso em: 02 mar. 2019.

SHEPHERD, D.. Portuguese speakers. In: SMITH, B.; SWAN, M. (orgs.). Learner English. 2. ed. Cambridge: Cambridge University Press, , 2001, p. 113-128.

SILVEIRA, R.. Ensino de pronúncia e a discriminação de padrões silábicos. DELTA - Documentação e Estudos em Linguística Teórica e Aplicada, São Paulo, v. 27, n. 01, p. 21-36, 2011. Disponível em: <https://revistas.pucsp.br/ index.php/delta/article/view/19913/14809>. Acesso em 27 set. 2020.

SOUZA, H. K. Brazilian EFL learners' awareness about L2 phones: is mall pronounced as 'mal'?. Trabalhos em Linguística Aplicada, Campinas, v. 56, n. 1, p. 235-258, Jan./Abr. 2017. Disponivel em: <http://www.scielo.br/pdf/ tla/v56n1/0103-1813-tla-56-01-00235.pdf>. Acesso em: 14 mar. 2019.

SOUZA, R. V. F. O conceito de "gameplay experience" aplicado à localização de games. Scientia Traductionis, Florianópolis, n. 15, p. 8-26, 2014. Disponível em: <http://dx.doi.org/10.5007/1980-4237.2014n15p8>.

THOMAS, E. R. Phonological and Phonetical Characteristics of African American Vernacular English. Language and Linguistics Compass, s.l., v. 1, p. 450-475, 2007. Disponivel em: <https://onlinelibrary.wiley.com/doi/abs/10.1111/j.1749818X.2007.00029.x>. Acesso em: 27 nov. 2020.

ZIMMER, M.; SILVEIRA, R.; ALVES, U. K. Cognition and second language aquisition. In: ZIMMER, M.; SILVEIRA, R.; ALVES, U. K. Pronunciation instruction for Brazilians: bringing theory and practice together. Cambridge: Cambridge Scholars Publishing, 2009, p. 1-10. Disponível em: <https://www. cambridgescholars.com/download/sample/60100>. Acesso em: 14 mar. 2019. 


\section{$E_{p}$}

O Brasil referenciado...

v. 11 (2) 1-24 maio-ago 2021

22

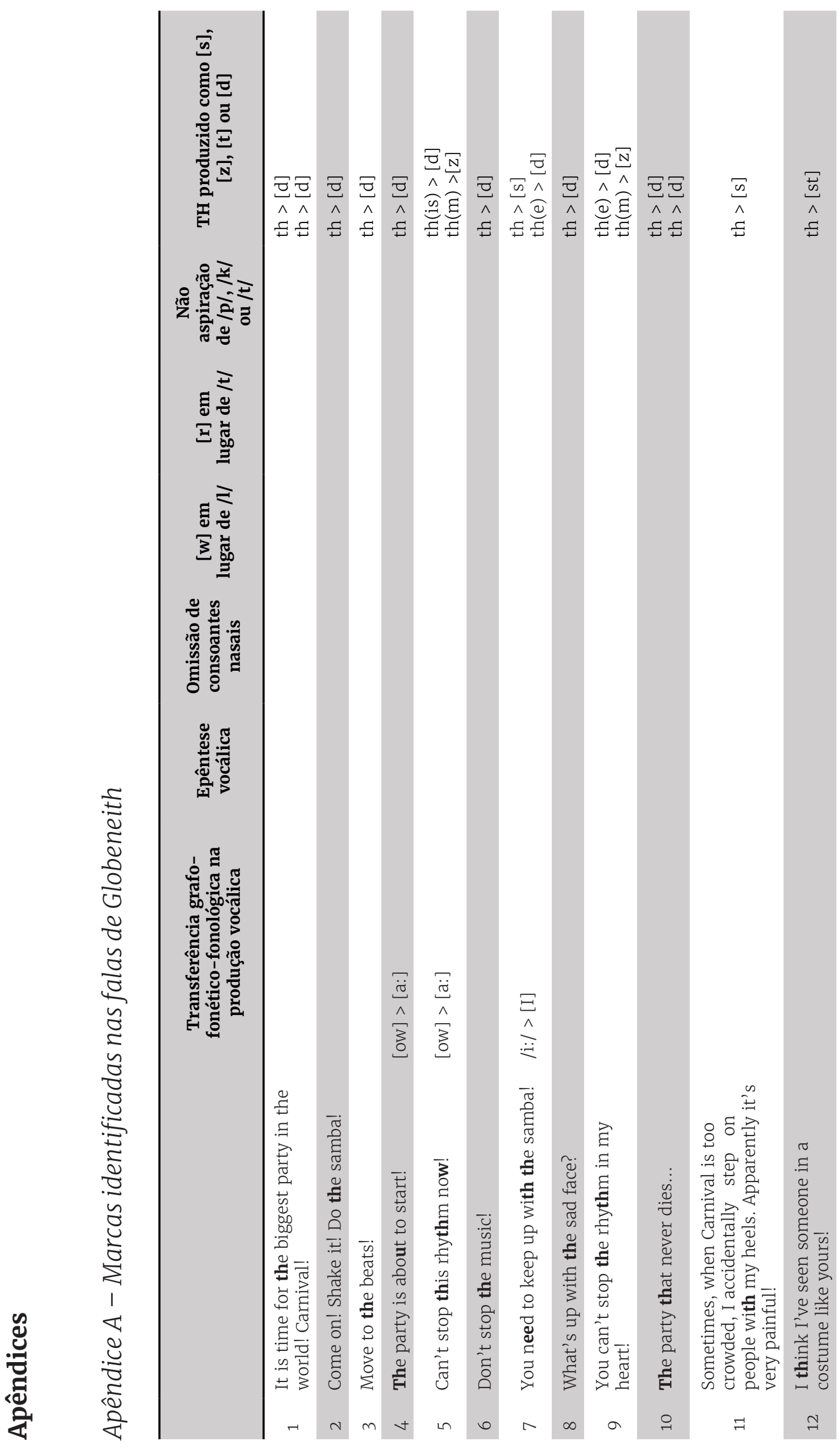




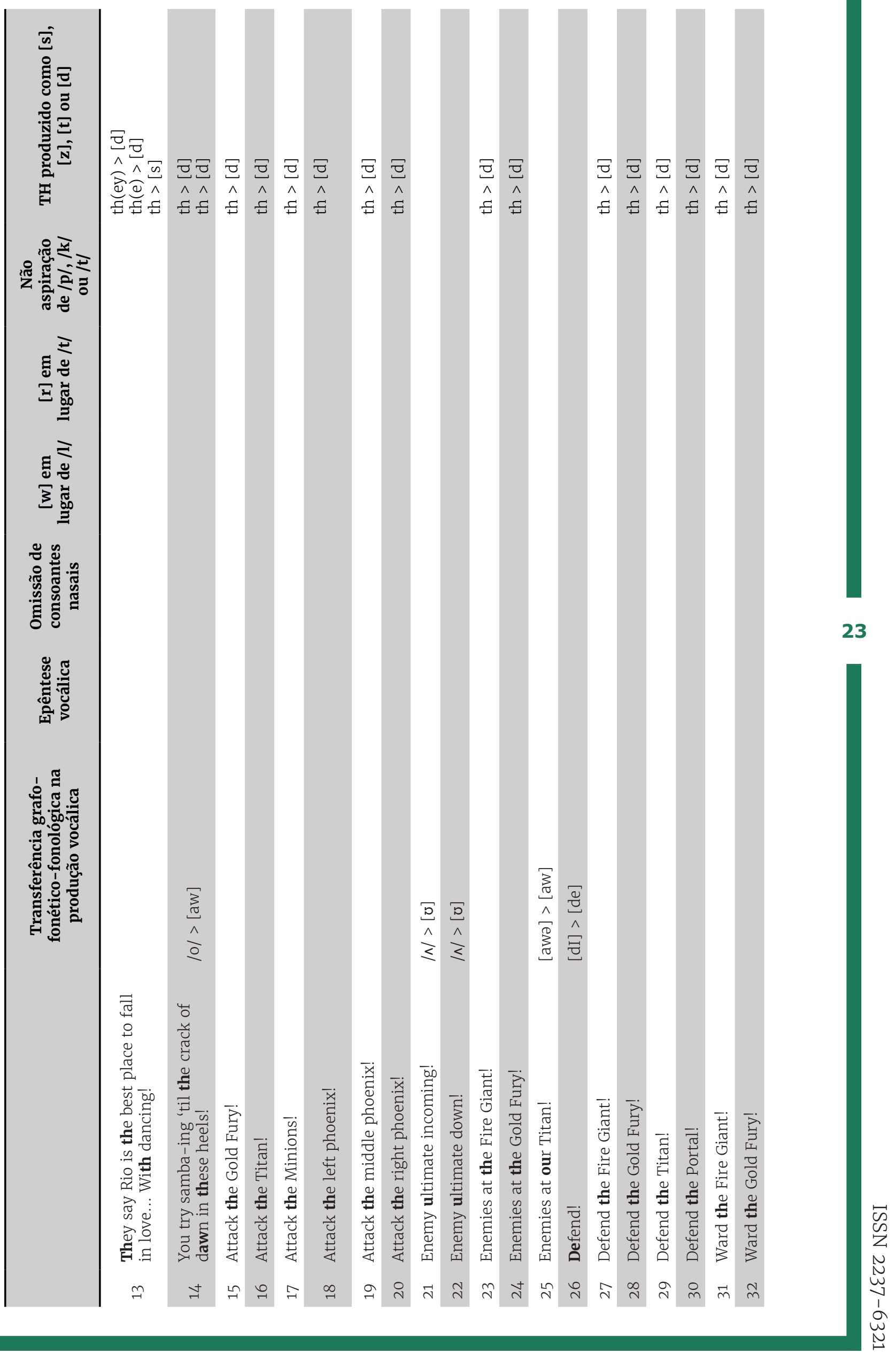




\section{$E_{p}$}

V. 11 (2) 1-24 maio-ago 2021

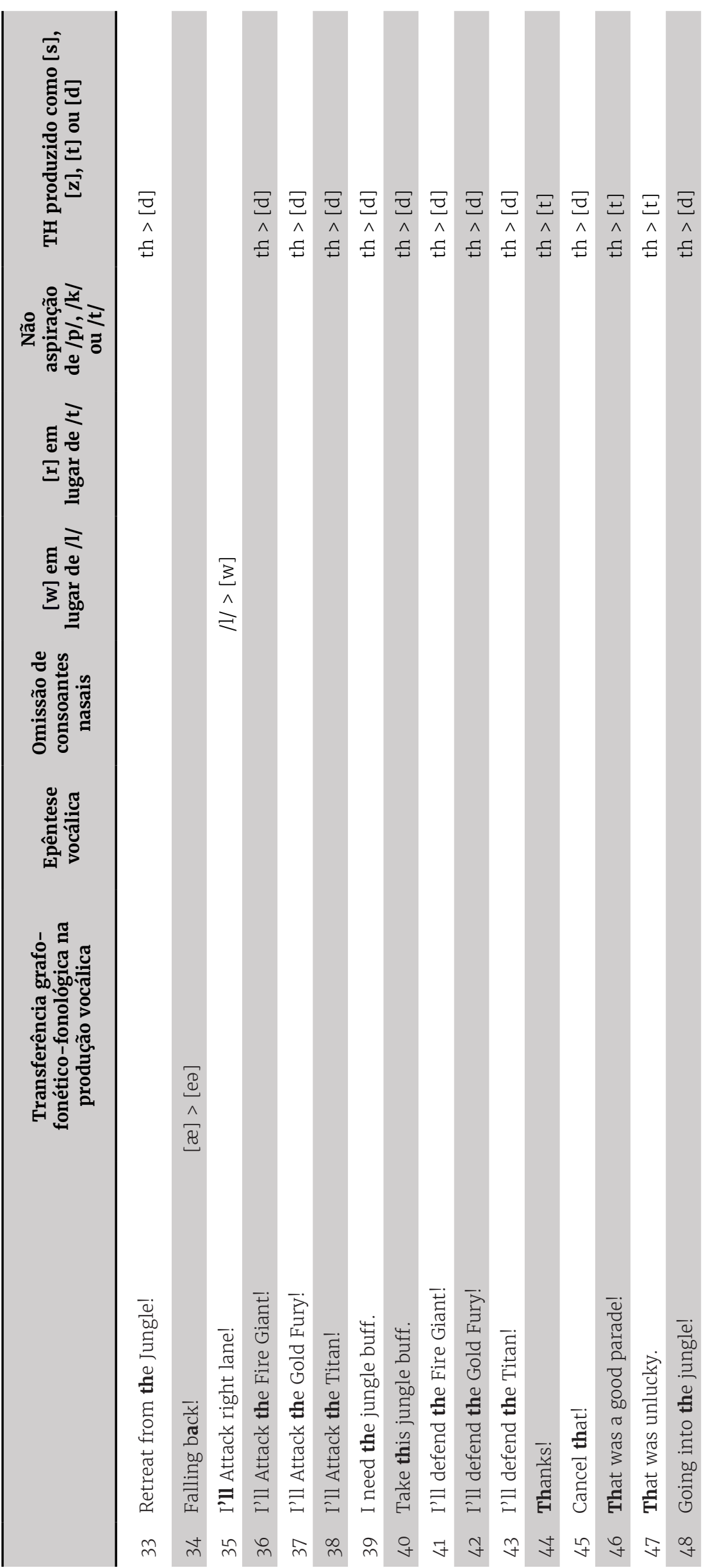

